\title{
Old Collier Golf Club Methods
}

This case study was produced in 2010 as part of the Landscape Architecture Foundation's Landscape Performance Series pilot. LAF staff worked with representatives of firms to document the project and its environmental, social, and economic benefits.

To cite:

Landscape Architecture Foundation. "Old Collier Golf Club." Landscape Performance Series. Landscape Architecture Foundation, 2010. https://doi.org/10.31353/cs1421

The full case study can be found at:

https://landscapeperformance.org/case-study-briefs/old-collier-golf-club 
Old Collier Golf Club - Naples, FL

Methodology for Landscape Performance Benefits

\section{Environmental}

- Protects 53 acres of mangrove and wetlands bordering the Cocohatchee River as a wildlife preserve.

Figure from design, plans, and construction documents, as required by permit from the Florida Department of Environmental Protection (DEP) since the Cocohatchee River is designated an Outstanding Florida Water (OFW).

- Retains on-site rainfall in addition to runoff from a nearby neighborhood for a 25-year storm event using 11 water management lakes, which keep pollutant discharge to the river at or below permitted levels.

Figures from design, plans, and construction documents. As a permit condition, the South Florida Water Management District required that the golf course retain water draining into, as well as falling on, the site, for a 25 -year storm event. The Naples Park Neighborhood runoff is managed on site.

- Established 109 acres of interconnected native upland scrub habitat by preserving 45 acres and creating 64 new acres. This habitat supports the vulnerable gopher tortoise among other species.

Figure from design, plans, and construction documents. Permit conditions required preservation of 45.6 acres of upland scrub. The Florida Game and Fresh Water Fish Commission required preservation of existing habitat for the gopher tortoise.

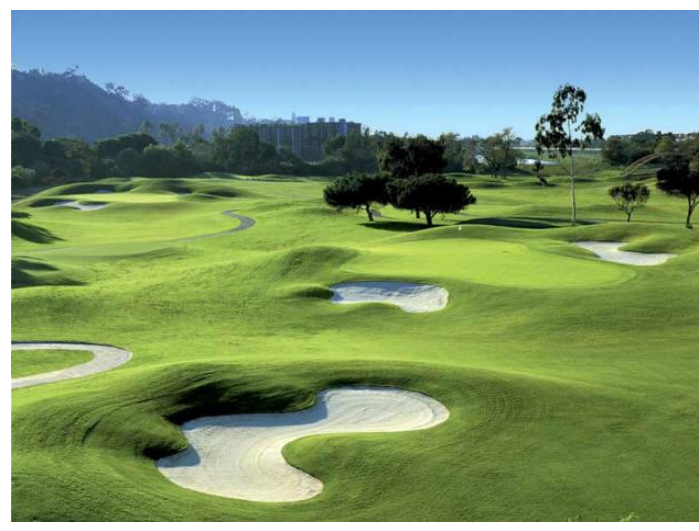

Many conventional golf courses feature holes that flow together and are only connected by the rough. There are no edges, protected native habitat areas or patches of habitat; they have all been cleared.

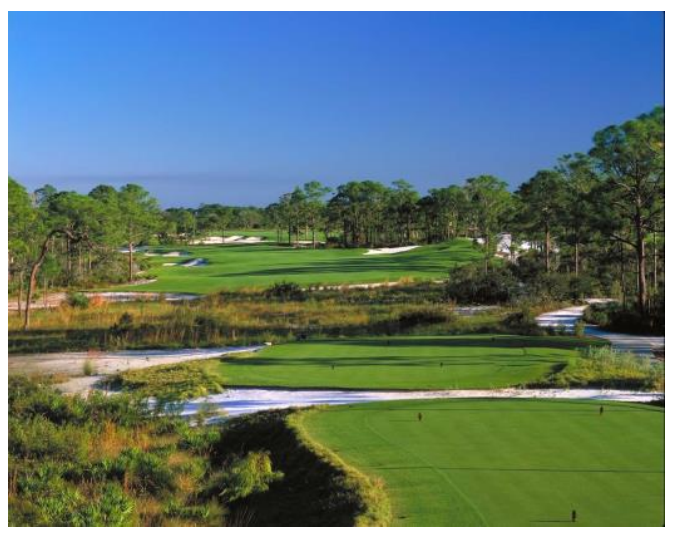

Old Collier GC features limited turf areas (77acres), protected native and habitat areas, cross-connections to wildlife patches, and large buffers to surrounding homesites. 
- Increased the number of bird species on the site from 60 to 118, including nesting bald eagles, osprey, and purple martins. The site has also seen a significant increase in local fauna, including alligators, foxes, and gopher tortoises.

Information from interviews with Golf Course Superintendent Tim Hiers. Counts and on-site assessments were carried out by Audubon International.

\section{Economic}

- Saves $\$ 35,000$ annually in water use compared to a typical golf course by using brackish water from the adjacent Cocohatchee River for irrigation.

The $\$ 35,000$ savings estimate was conducted by Golf Course Superintendent Tim Hiers by comparing water and utility bills from Old Collier to costs from a nearby "typical" golf course where he previously worked. While this estimate is helpful, Tim explained that comparing golf course budgets is usually ineffective because each property varies in climate, soil composition, water quality, shade, grass type, cart traffic, etc. Furthermore, since Old Collier was the first golf course in the world to irrigate exclusively with brackish water, there were no precedents for this type of comparison.

\section{\&RMURP SDUVRQ}

- Reduced turf acreage saves $\$ 20,000$ annually in nitrogen application costs and reduces man hours, fuel consumption, and machinery for maintenance.

This estimate was done by Tim Hiers based on golf courses he worked at previously and on statistics from the Golf Course Superintendents Association of America (GCSAA), which collects and publishes information on all U.S. golf courses, including turf acreage, fertilizer and pesticide use, and irrigation.

- Irrigating at night saves \$1,700 SHUP RQMUlin peak electrical demand charges and is more efficient with less misting and evaporation from wind and sun.

Irrigating from $11 \mathrm{pm}$ to $5: 30 \mathrm{am}$ avoids a Collier County demand charge for irrigating during peak demand times ZKIFK DP RXQN VR SHUP RQKK. There is less wind at night, resulting in less irrigation drift, and no sun, resulting in less evaporation.

Further, the highly efficient irrigation system features bigger pipes that use less PSI, pull less amps, and use less power. All this, combined with lower sprinkler angles leads to bigger water

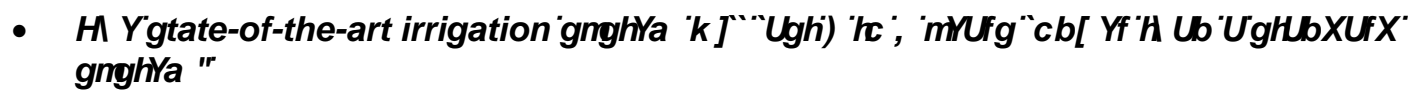

The state-of-the-art irrigation DVR Q\&\& ROUU ZKIFK FRWW P LORQVR LQWDOKDV D

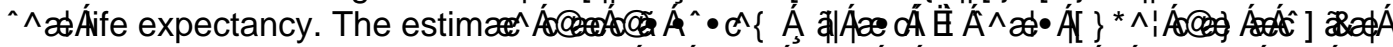
V WAP comes from Tim Hiers, based RQKIV P DQ \ HDWR H SHUHCFHLQZRUVQ ZLKK

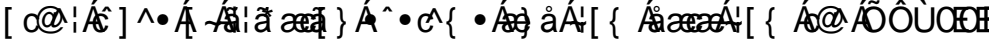

